it that even in the Royal Maternity Charity cases of puerperal fever arose? The truth is, they are more likely, for reasons which I shall hereafter explain, to carry the seeds of puerperal fever than are men. The occurrence of series of cases of puerperal fever in the practice of midwives is as common as amongst medical men. And I have had occasion for this reason to advise midwives of the Royal Maternity Charity to suspend their duties for a time.

I will next examine more critically the grounds upon which the doctrine of the spread of puerperal fever by the carrying of cadaveric poison, or of the specific poisons of zymotic diseases, rests.

ON

\section{FIVE CASES OF STONE IN THE BLADDER WHERE NO SURGICAL EXAMINATION HAD BEEN MADE.}

\author{
BY BARNARD HOLT, F.R.C.S., \\ SENTOR SUBGEON TO THR WESTMINSTER HOSPITAL.
}

CASE 1.-In the month of June last, the brother-in-law of a gentleman in the country gave me the following history of his relation :- "Three years since, while travelling for the benefit of his health, my brother-in-law was seized with pain in the back of a sufficiently severe character to require him to be confined to the house. The surgeon he consulted prescribed some medicines, and in a few days he continued his journey. Some months afterwards he had another and a more prolonged attack, the pain this time extending down the right side to the groin. This attack was also controlled by medicines; but was shortly afterwards followed by uneasiness in the bladder, and a more frequent desire than usual to pass his water. This continued for some months, the frequency varying with exertion, and he consulted a physician in Paris, who apparently studied his case with great care, and prescribed for him. The urine was tested; but no examination of the bladder was made. After remaining under the care of this gentleman for some months, his symptoms became more marked, the irritability of his bladder increased, and, when emptied, he experienced pain at the extremity of the penis. Blood was occasionally mixed with the urine, and he had greater difficulty in micturating at one time than another. A second and a third physician were from time to time consulted ; but no surgical examination was made." The patient, continuing to get worse, came to London, and placed himself under the care of a physician of high repute, who, after examining his urine, most carefully gave it as his decided opinion that there was no stone. No examination of the bladder was suggested. After remaining under the care of this gentleman for many months without any relief, but, on the contrary, his symptoms becoming monthly more aggravated, in despair at obtaining ease from medical means, he consulted a homoeopath, then a hydropath, and, not obtaining any alleviation of his suffering, eventually a clairvoyant residing somewhere in London, who by correspondence (for he was now staying in Devonshire) informed him he was suffering from irritability of the bladder, which she could cure. Of course this was fallacious; and being still in great misery, and having, as he imagined, exhausted every source, he abandoned himself to his fate. Feeling tolerably certain as to the cause, $I$ urgently requested that he should come to town; and upon arriving at the Great Western Hotel, where he was seen by Mr. Tatham and myself, we, upon examination, immediately detected two calculi in the bladder. Of course the mystery was at once solved; and although at this time his health was materially involved, yet there was some hope that an operation might be successful. On the third day after his arrival in town, the stones were broken, and for the first few days he progressed favourably; but subacute inflammation of the bladder supervened, and the operation of lithotrity could not be proceeded with. He was now seen by Mr. Fergusson, when we decided that lithotomy should be had recourse to. The median operation was performed, and the calculi removed. The irritability of the bladder, however, continued as aggravated as before; and he subsequently died. At a post-mortem examination, the bladder was found extensively diseased, greatly hypertrophied, and both kidneys in an advanced stage of disorganization.
CASE 2.-J. G-_, aged fifty-five, was desired by his surgeon in the country to consult me as he passed through London, in consequence of great irritability of the bladder, which was supposed to be dependent on stricture of the urethra. His history was of the usual description : frequency of micturition; pain at the extremity of the penis; occasional passage of blood; inability to ride in a jolting vehicle; a sense of weight in the rectum, \&c. He had been under medical treatment for two years, and during that time had been treated for irritable bladder, without, however, the slightest relief excepting that which was obtained from the administration of opium. The surgeon who directed this gentleman to consult me had attempted and failed to pass an instrument into the bladder, and hence came to the conclusion that he was suffering from stricture. Upon examination a No. 10 sound passed with great ease, and a calculus was at once struck. The patient subsequently was subjected to lithotrity, which I was compelled to repeat five times before the whole stone was removed. He is now perfectly well.

CASE 3.-Mr. $\mathrm{L}_{-}$, a solicitor, consulted me on behalf of his son, a boy ten years of age, who for two years had been suffering from the usual symptoms of stone in the bladder. The boy was very intelligent, but timid, and he had doubtless masked his symptoms from fear of an examination; his sufferings were, however, readily appreciable after micturition; and as he always sat on the edge and not on the seat of his chair, his father concluded there must be something seriously the matter with him. He had been under various kinds of treatment for two years, but the bladder had not been examined. A stone was at once detected, which I subsequently removed by median lithotomy. It measured an inch in length, and was more than half an inch broad. He recovered without a bad symptom.

CASE 4.-The Rev. … was brought to me by a neighbour, a physician, suffering from all the symptoms of stone. In 1848, while abroad, he noticed a sandy sediment in his urine, which was occasionally mixed with mucus; but at this time there was not any symptom referred to the bladdler. In $\mathbf{1 8 5 6}$ he had a severe attack of pain in the left kidney, which yielded to cupping, \&c.; and in 1861 he had another attack, more severe than the former, and he afterwards voided two small calculi. Irritation of the bladder remained, and he was compelled to micturate more frequently than usual; he also experienced pain at the end of the penis after voiding his urine. No surgical exanination was made, but he was desired to go to Ripoldsau and drink the waters. From these he derived no benefit, and all his symptoms increased. In 1863, after riding in Smyrna, he passed blood; his bladder-irritation became severe; he walked with difficulty; and could not ride in any jolting vehicle, without great pain. He again consulted a surgeon, who did not examine him, but told him be had no stone, but that he had a tendency to it. In 1865 he consulted. my neighbour, who, at once suspecting the cause, hr. nght him to my house, when, upon introducing a sound, a large calculus was detected. Being a fat plethoric man of sixty, the operation of lithotrity was decided upon; and, by the subsequent introduction of the lithotrite, one stone, of the lithic-acid variety and exceedingly hard, measuring an inch and a third in diameter, was broken up. A second could be readily felt; and there was every reason to believe, from the quantity of débris that was subsequently removed, that the bladder had contained a third. This complication necessarily prolonged his cure, more especially as, although the stone was thoroughly broken, he was unable to pass the fragments, and it was necessary to remove them with the spoon. After twelve operations the whole of the calculi were removed, and he is now quite well. I may add that, with one exception, he did not suffer from rigors, although for years he had been subject to frequent attacks of intermittent fever.

Case 5. - This case somewhat differs from the former, in the fact that the patient had only recently consulted his surgeon, although he had been suffering for many months. When he did so, the surgeon suggested a consultation. A stone was detected, and after three lithotriptic operations the whole stone was removed. The patient is now perfectly well.

The interest that attaches to the above cases is mainly due to the fact that the patients, although suffering from all the symptoms of stone in the bladder, were not surgically examined. Why is this? Upon what grounds does the physician continue to treat his patient month after month without benefit, and yet not have the bladder surgically explored? We are all aware that the symptoms of stone may be present, and yet depend on disease of the kidney or bladder independently of any concretion; but, on the other hand, there is a 
large proportion of cases where such concretions are the sole cause of the suffering, and when overlooked will give rise, sooner or later, to disease of the bladder, which militates very much against the patient's recovery. Why should not all patients so suffering be examined by a surgeon? The examination, properly made, gives but the least modicum of pain, and $I$ unhesitatingly assert never creates mischief, and by it you are at once in possession of the positive or negative evi- dence of the symptoms being dependent on a foreign body. The first was a lamentable case, for it occurred in a gentleman - of high position, and one who, from his special amiability, was endeared to all his friends. Unfortunately in his case remedial measures were had recourse to when too late, and he sank. In the others an operation succeeded in saving life, but the patients were subjected to repetitions of the operation, which were rendered necessary either from the size of the stone or from there being more than one. If these cases had in the first instance been diagnosed correctly, the operation of lithotrity would have been most successful, and have been completed in one operation; but, as is almost always the case, the patient is permitted to continue suffering without the bladder being examined, until the stone has attained a size which renders it impossible for the surgeon to sufficiently crush it at one operation. That this is so is clear from the rarity of finding a small stone in an adult or even in a child, and yet the symptoms are sufficiently confirmatory to warrant an examination, by which all doubt as to the nature of the case may be at once removed. I therefore venture to suggest that the bladder should be examined in every instance where the symptoms of stone exist; that the sound should be moderately small, with a short curve and flat handle; that in all cases of doubt the sounding-board should be used, by which the minutest particle can be at once detected; and lastly, that the patient should be examined in different positions, and with the bladder both full and empty.

Sarile-row, Sept. 20th, 1865.

ON THE

\section{ASSIMTLATION OF FAT IN CONSUMPTION.}

\section{A Third Report of Cases treated with Pancreatic Emulsion ai the Royal Infirmary for Diseases of the Chest, City-road.}

BY HORACE DOBELL, M.D., PHXSICIAN TO THE INFTRIIRY.

Ir my former reports I have referred to the able assistance I have received, in my experiments on pancreatic juice, from Mr. Feathorn; and $I$ am sorry to have to state that, since my last report of June 10th, Mr. Feathorn has found his other engagements too numerous to allow him to prepare the emulsions, now that the demand has increased through other medical men prescribing them as well as myself.

We have, however, been able to make great improvements in the mode of extracting the active principles of pancreatic juice and of preparing pancreatic emulsion; and I have recentiy received the most valuable assistance in this matter from Mr. Schweitzer, the scientific chemist in the establishment of Messrs. Savory and Moore. In future, therefore, pancreatine and pancreatic emulsions will be prepared by Messrs. Savory and Moore. I am happy to be able to make this announcement, because it is a guarantee that these delicate remedial agents will be prepared with systematic accuracy, and that every opportunity will be given for their general use by medical men. I have requested Messrs. Savory and Moore to keep the preparations of pancreatic juice in the following Forms:-

1. Pancreatine in capsules or globules-to be swallowed soon after a full meal. Each to represent a certain emulsiiying power.

2. 3increatic emulsion of solid fat.

3. Pancreatic emulsion of cod-liver oil.

4. Pancreatic emulsion of lard oil.

I wrould suggest to those who have the opportunity of doing so, to try the effects of these preparations in cases of diabetic ryasting, and in cases of disease of the pancreas, where the secretion of the organ is arrested or deteriorated; for it is probable that in these cases life may be prolonged by the artificial introduction of pancreatine.

My own experience of the use of pancreatine has, at present, been almost confined to the treatment of tuberculosis, and the following is a summary of cases treated with pancreatic emulsions of lard oil and of suet since my last paper :-

Summary of 38 Cases of Consumption : 27 tReated with Pancreatic Emulsion of Lard OIL, aNd 11 with Pan. CREatic Emulsion of Suet.

\section{First stage (advanced).}

9 cases in the lst stage treated with larl-oil emulsion-Condition on discharge measured by general symptoms: Improved, 8 ; worse, 1.

Condition on discharge measured by physical signs: Improved, 5; stationary, 3 ; worse, 1 .

Cod-liver oil agreed, 4 ; disagreed, 5 .

Emulsion agreed, 9; disagreed, 0.

\section{Second stage.}

9 cases treated with lard-oil emulsion-Condition on discharge measured by general symptoms : Improved, 8 ; worse, 1 .

Condition on discharge measured by physical signs: Improved, 5 ; stationary, 2 ; worse, 2.

5 cases treated with suet emulsion-Condition on discharge measured by general symptoms : Improved, 3; stationary, 1 ; worse, 1 .

Condition on discharge measured by physical signs: Improved, 2 ; stationary, 3.

Cod-liver oil agreed, 5 ; disagreed, 9 .

Emulsion agreed (lard oil 8, suet 5), 13; disagreed (lard oil), 1.

\section{Third stage.}

9 cases treated with lard-oil emulsion-Condition on discharge measured by general symptoms: Improved, 7 ; worse, 2 .

Condition on discharge measured by physical signs : Im. proved, 3 ; stationary, 5 ; worse, 1 .

6 cases treated with suet emulsion-Condition on discharge measured by general symptoms: Improved, 5 ; worse, 1 .

Condition on discharge measured by physical signs : Improved, 3 ; stationary, 2 ; worse, 1 .

Cod-liver oil agreed, 5 ; disagreed, 10 .

Emulsion agreed (lard oil 8, suet 6), 14; disagreed (lard oil), 1 .

Total results of the 27 cases treated with lard-oil emulsion:-

Measured by general symptoms: Improved, 23; worse, 4.

Measured by physical signs : Improved, 13 ; stationary, 10; worse, 4.

Total results of the 11 cases treated with suet emulsion:-

Measured by general symptoms: Improved, 8 ; stationary, 1 ; worse, 2.

Measured by physical signs: Improved, 5 ; stationary, 5; worse, 1 .

Of the total number of 38 cases-

9 were in the first stage (advanced).

$14, \quad$ second stage.

$15 \quad, \quad$ third stage.

Cod-liver oil agreed, 14 ; disagreed, 24.

Emulsion agreed, 36 ; disagreed, 2.

The effects of the emulsions on the digestive functions may be partly learned from the following short extracts from some of the cases:-

CASE 55.- When he began emulsion, appetite was very bad, and it was difficult to take the milk with emulsion ; but appetite improved as he went on, and he took emulsion twenty weeks with great advantage, buying it for himself after his discharge because he missed it when it was discontinued.

CASE 56.-After taking oil for a long while and losing flesh and strength, he gained $S \mathrm{lb}$. in seven weeks under emulsion, and got quite strong.

CASE 57.- Had taken oil off and on for twelve months, but steadily lost flesh and strength. Of late oil has disagreed, and motions are pale. Emulsion agrees; appetite improves, and she gains flesh and strength rapidly; motions no longer pale. for three months, but it disagreed latterly, and she had steadily lost ground in all respects. Emulsion agrees well, and after a fortnight she is surprised at her improvement. At the fourth week she writes: "I gain strength daily. Appetite much improved. I have not such a dislike for fat, and I now can take cod-liver oil as well as emulsion."

CASE 64.-Oil makes him sick. Emulsion keeps down when 